\title{
Reseña bibliográfica de: Bjerg, M. (2019). Lazos rotos. La inmigración, el matrimonio y las emociones en la Argentina entre los siglos XIX y XX. Bernal: Universidad Nacional de Quilmes. 125 pp. ${ }^{1}$
}

Palabras clave: Historia de las Emociones; Inmigración; Historiografía; Matrimonio.

Keywords: History of Emotions; Immigration; Historiography; Marriage.

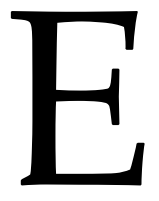

n las últimas décadas, la inmigración europea ha constituido un tópico recurrente en la historiografía local, especialmente en lo que refiere a los procesos de conformación del estado nacional en las postrimerías decimonónicas. Sendos abordajes pusieron de relieve la arista cuantitativa de la afluencia ultramarina, su impacto demográfico y el impulso en la modelización de una economía moderna a las puertas de la nueva centuria. Sin embargo, tanto la experiencia colectiva y subjetiva de la migración como la vida cotidiana de quienes emigraron no devinieron en igual objeto de interés para el campo de estudios históricos.

Aunque centradas en Buenos Aires, diversas investigaciones han comenzado a indagar la heterogeneidad de los grupos inmigrantes, explorando las redes y la sociabilidad urbana, junto con las tensiones que el incipiente estado nacional concitaba en el terreno de la política inmigratoria. Recientemente, otros interrogantes pusieron en tensión los modos en que dicha experiencia tuvo lugar en Argentina en el entresiglo, en particular aquellas lecturas que la han concebido como un fenómeno social exitoso, de carácter armónico, uniforme y lineal.

El libro Lazos rotos. La inmigración, el matrimonio y las emociones en la Argentina entre los siglos XIX y XX se distancia de estos esquemas al complejizar el desembarco de españoles e italianos en estas costas a través de un enfoque histórico centrado en las emociones. ¿Qué son las emociones? ¿Tienen una génesis y un devenir histórico? ¿Cómo se relacionan con la inmigración? Las emociones han comenzado a ocupar un lugar preponderante en las ciencias sociales, al menos, desde el último tercio del siglo XX, cobrando mayor trascendencia en los primeros años del presente siglo como resultado

\footnotetext{
${ }^{1}$ La autora es actualmente Becaria de Docencia e Investigación del Departamento de Ciencias Sociales de la Universidad Nacional de Quilmes.
} 
de un interés analítico ubicado en derredor a la agencia de los sujetos en determinados períodos históricos.

El reciente trabajo de María Bjerg busca poner en tensión no solo los abordajes historiográficos más tradicionales en torno a la inmigración, sino también la contracara de los desplazamientos migratorios desde un prisma que concibe a las emociones como prácticas y vectores socio culturales con un disímil recorrido y actuación histórica. La vinculación entre cuerpo, lenguaje y emociones oficia de andamiaje para comprender los márgenes de negociación y resignificación, las continuidades y los cambios que emergieron en las trayectorias de los varones y las mujeres abordadas.

La autora hace de los expedientes judiciales su principal vía de indagación, deteniéndose en aquellos casos donde el impacto afectivo de la inmigración trastocó las relaciones conyugales, haciendo brotar emociones como la ira, la desilusión, la tristeza o la rabia. En consecuencia, el trabajo procura recrear las tramas sociales que circundaron a sus protagonistas con el objeto de recuperar sus voces, sus desdichas, bajo el supuesto de que las fuentes judiciales suelen advenir elocuentes debido a su riqueza documental $\mathrm{y}$ a las diferentes mediaciones que las impregnan.

Sin embargo, acceder al testimonio emocional, a sus prácticas y a sus subjetividades desde estos registros supone navegar por los claroscuros de la interpretación, el escrutinio y la semántica jurídica durante un período signado por la redacción de códigos, leyes y una incipiente cultura litigante.

Entonces, ¿cómo emana una emoción en un expediente? ¿De manera textual? ¿Es posible rastrear un conjunto de emociones sin descuidar su construcción social e históricamente situada? ¿Cómo se despliega y verbaliza una emoción en un escenario judicial, social y cultural más amplio? Al complementar sus fuentes primarias con registros provenientes de la prensa, de documentación oficial, de censos y de cartas, el libro recompone las biografías, los orígenes y el devenir de los protagonistas en Argentina a fin de conocer sus motivaciones, sus penas, la fibra íntima de los matrimonios y los alcances del proyecto inmigratorio sin proponer lecturas homogéneas, ecuménicas y lineales.

Abocado a estudiar los periplos burocráticos, las reyertas y el corolario tormentoso de la inmigración en las relaciones afectivas, el estudio articula la dimensión subjetiva y experiencial de los actores con una escala más amplia concerniente a las prescripciones emocionales coetáneas. Al reconectar prácticas con su universo de acción, el libro repiensa los alcances y los intersticios de la agencia emocional de quienes litigaron y expusieron su "intimidad" a los ojos de jueces, magistrados y letrados, al tiempo que indaga sobre la tensión entre la cultura de origen y el desenvolvimiento en espacios locales.

De esta manera, en el estudio se explora cómo la inmigración transfiguró las relaciones afectivas y familiares de los matrimonios inmigrantes en un contexto signado por un notable tránsito y movilidad social. Su hipótesis central es que los procesos migratorios participaron en la construcción de un orden emocional en el cual los sujetos 
apelaron a un repertorio emocional y negociaron un lenguaje emocional heterogéneo con los cuales dar sentido a sus prácticas en la arena judicial.

Este libro propone una agenda de investigación historiográfica preocupada por repensar las coordenadas de los estudios históricos en torno a las experiencias, las prácticas y sus mediaciones, así como también las implicancias epistemológicas, teóricas y metodológicas que acarrea colocar a las emociones en el centro de la escena historiográfica actual.

La autora opta por presentar sus fuentes primarias como casos, como pequeños puntos luminosos que irradian en una escala más general y en una dimensión más subjetiva, donde las vidas de quienes litigaron, ritmadas por el sufrimiento, el dolor, la angustia o la ira, alcanzan a la historiadora para interrogarla por las miserias emocionales y el imaginario de prosperidad que atraviesan a los sujetos involucrados. Es un abordaje zurcido a base de retazos, silencios, expectativas, proyectos, desgarros y trayectorias. Los casos minúsculos, pinceladas sustraídas del anonimato archivístico, operan como susurros, hilos de voz teñidos por la experiencia de litigar, confrontar y desenmascarar las consecuencias que la distancia le infligió a los modos de prodigar y expresar el afecto.

La intersección entre emociones, inmigración e historia se presenta como un intrincado triángulo interpretativo donde las disposiciones de género, y también de clase, revelan lenguajes y actuaciones emocionales al interior de un entramado patriarcal en donde las redes de contacto podían dirimir los destinos de los protagonistas. A menudo diferenciada, la gestión emocional en los fueros judiciales apeló a un repertorio de estrategias que articuló estatutos de género y nociones de moralidad. Asimismo, quienes conformaron el discurso jurídico, jueces, médicos y abogados, también reinterpretaron la agencia emocional disponible en esos espacios proponiendo una semántica propia y volcándola a los documentos que nutren la indagación histórica.

Gracias a una prosa fluida, amena y sensible, el texto proporciona al lector un acercamiento al floreciente campo de estudio de las emociones. Se destaca la proximidad y la rigurosidad con la que la autora se adentra en las historias de un puñado de inmigrantes que aspiraban a modificar, muchas veces, sus circunstancias materiales, sin imaginar lo que les depararía a nivel emocional y afectivo.

El libro se encuentra organizado en una introducción, cuatro capítulos y un epílogo. Su disposición no es azarosa, sino que procura movilizar conceptualizaciones centrales del campo de las emociones con motivo del tenor de los casos indagados. Su hilo conductor son emociones connotadas como "negativas", junto con las predisposiciones emocionales que ellas estimulan, como los celos, el honor o la honra. La complejidad del esquema argumental se agudiza conforme avanza tanto en la opacidad de las fuentes primarias a la hora de atender qué emociones se esgrimen y se encarnan, como en los desenlaces desafortunados que se estudian.

El capítulo uno se detiene en las sentencias de juicios por bigamia cometidos por varones inmigrantes, cuyas esposas quedaron supeditadas a la espera de un llamado de 
reencuentro, un retorno de sus maridos al país de origen o el esclarecimiento de las causas que dieron fin al intercambio epistolar. Las mujeres inmigrantes se embarcaron en extenuantes viajes en las últimas décadas del siglo XIX, cargadas de documentos e incertezas que las sumirían en engorrosos procedimientos judiciales cuyos repertorios emocionales, como la angustia, el rencor, la tristeza y la traición podían llevarlas a resignificar los vínculos matrimoniales.

El capítulo dos entreteje historias de abandono y fuga de los espacios domésticos protagonizados por mujeres como consecuencia de denuncias por adulterio realizadas por sus cónyuges. En ellas, una madeja de emociones floreció como resultado de la negociación, la vivencia y la sociabilidad dentro de un régimen emocional y un contexto sociocultural volátil que condicionaba la cotidianeidad de los matrimonios. En este sentido, las vidas de las cuatro mujeres, sus maridos y sus amantes, dejan entrever la mutación y la significación que la vergüenza, la compasión, la venganza y el arrepentimiento fueron adquiriendo en el transcurso de las causas judiciales, donde la violencia física, el abandono, la estrechez económica o la soledad configuraron un entramado común.

El tercer capítulo indaga sobre procesos judiciales en los que las lesiones físicas constituyeron el eje principal. Frente al adulterio, la fuga, suposiciones de infidelidad o rencillas por la subsistencia económica, las agresiones y la violencia operaron a manera de estrategia para sortear los constreñimientos de los maridos en los espacios domésticos y acceder al mercado de trabajo, donde la connotación del dinero podía significar un agravio al honor masculino si era la esposa quien proveía a la familia. Al mismo tiempo, las abrasiones y las lesiones condensaron una menor restricción en la expresión de la ira por parte de los varones como resultado de la desobediencia de las mujeres.

Finalmente, el último capítulo aborda dos casos de uxoricidios, una figura dentro del Código Penal que tipificó la muerte de uno de los cónyuges a manos de su pareja, en los que las víctimas fueron mujeres. Las fuentes nos narran la situación de dos matrimonios en los cuales los celos, la afrenta al honor, las pulsiones, las exaltaciones violentas y el remordimiento, movilizaron la agencia emocional de los varones imputados en las postrimerías del siglo XIX.

En ambos, los homicidas alegan un repertorio emocional similar, pero distinguiéndose en el decurso de sus sentencias. Se destaca el peso que los celos, la amonestación y la reprobación hacia la conducta femenina, y "temperamentos nerviosos" tuvieron a la hora de formular sentencias. A la zaga, los diarios locales exaltaron la intensidad de los conflictos domésticos al inscribirlos en un relato amoroso atizado por "pasiones desbordadas" causadas por las sospechas de engaño e infidelidad.

Los matrimonios y los lazos conyugales obturados por el proyecto de la inmigración que se hilvanan a lo largo del libro nos permiten acceder no solo a un período histórico atravesado por la movilidad, las transformaciones sociales y las ambiciones modernizantes, sino también a las experiencias de quienes las transitaron, habitaron, negociaron y significaron. A través de las emociones, los protagonistas dieron sentido a 
una cotidianeidad que se presentaba de forma dinámica, en donde el cariño podía anudarse a la obediencia y transformarse en discrepancias, en donde el discurso judicial podía representar una arena de reparación emocional y moral a la vez que una escena en la cual desplegar una agencia emocional más flexible.

Para los varones inmigrantes, el honor masculino condensó las prerrogativas de una sociedad patriarcal que los ubicaba como representantes y protectores de una familia nuclear. En cambio, las mujeres encontraron un margen más estrecho de acción para revertir las violencias y las disputas en los espacios domésticos y en los fueros.

En suma, Lazos Rotos contribuye a sustraer a las emociones de un ostracismo historiográfico y a repensar las experiencias en torno a la inmigración desde un prisma que articule experiencias pequeñas con escalas y procesos socioculturales más amplios. De esta manera, permite poner en tensión la universalidad y la estabilidad de las emociones a lo largo del tiempo, así como también pensar los diferentes procesos y períodos históricos desde sus implicancias emocionales.

\section{Ailin Basilio Fabris Centro de Estudios en Historia, Cultura y Memoria/ Universidad Nacional de Quilmes, Argentina ailinbasiliofabris@gmail.com}

Para citar este artículo:

Basilio Fabris, Ailin (2020). Reseña bibliográfica: “Bjerg, M. (2019). Lazos rotos. La inmigración, el matrimonio y las emociones en la Argentina entre los siglos XIX y XX. Bernal: Universidad Nacional de Quilmes. 125 pp." Anuario de la Escuela de Historia Virtual, 18, 272-276. 